\title{
Does the Waiting Period for Genetic Tests Affect the Prognosis in Chemotherapy-Treated de novo Metastatic Non-Small Cell Lung Cancer Patients without a Driver Mutation?
}

\author{
Serdar Arici ${ }^{a}$ Abdullah Sakin ${ }^{b}$ Ruhper Cekin ${ }^{a}$ Saban Secmeler ${ }^{a}$ \\ Nurgül Yasar ${ }^{a}$ Sener Cihan ${ }^{a}$ \\ a Department of Medical Oncology, University of Health Sciences, Okmeydani Training and Research Hospital, \\ Istanbul, Turkey; ${ }^{b}$ Department of Medical Oncology, Yuzuncu Yil University Medical School, Van, Turkey
}

\section{Keywords}

Duration between diagnosis and the start of first-line chemotherapy · Non-small cell lung cancer · Driver mutations

\begin{abstract}
Introduction: The length of the necessary waiting period to test driver mutations may generate anxiety in patients and clinicians. For this reason, an investigation was conducted to determine whether the duration between diagnosis and the start of first-line chemotherapy (DDC) in non-small cell lung cancer (NSCLC) patients without driver mutations has an impact on prognosis. Methods: The study included 303 de novo metastatic NSCLC patients without a driver mutation and patients were divided into 2 groups according to DDC: $\leq 30$ days (group A) or $>30$ days (group B). The determinant factors for progression-free survival (PFS) and overall survival (OS) were examined by Cox regression analysis. Results: The mean DDC was calculated as $38.2 \pm 54.5$ days. The number of patients in group A and B were 183 and 120, respectively. The median PFS in groups A and B was 5.0 and 6.0 months $(p=0.268)$ and the median OS was 10.0 and 11 months, respectively ( $p=$ 0.341). Univariate and multivariate analyses revealed that DDC was not a factor associated with PFS and OS. Conclusion: Our results show that a higher DDC was not associated with a worse prognosis in metastatic NSCLC patients without driver mutations. In this context, it is safer for patients and their physicians to wait for test results before starting chemotherapy.

(c) 2020 S. Karger AG, Basel
\end{abstract}

\section{Introduction}

Lung cancer (LC) is the most common cancer worldwide and the most common cause of cancer-related death. In 2012, approximately 1.8 million patients had LC worldwide, with 1.6 million deaths occurring in the same year. Due to recent innovations and developments in LC treatment, mortality has started to decrease in both men and women, but prognosis is still poor, with the 5-year survival rate being $<15 \%$. Non-small cell LC (NSCLC) accounts for $85 \%$ of all LC cases $[1,2]$. Adenocarcinoma (AC) and squamous cell carcinoma (SCC) are the most common types of NSCLC $[3,4]$.

The presence or absence of a driver mutation, such as mutated epidermal growth factor receptor (EGFR), anaplastic lymphoma kinase (ALK) rearrangements, c-ROS oncogene 1 (ROS 1), and increasingly other mutations for which a specific inhibitor is available, is a key determining factor in the choice of initial therapy for patients with advanced lung AC or selected SCC, for example those with a history of light smoking or no smoking at all, and other non-small cell carcinomas not otherwise specified (NSCLC-NOS) $[5,6]$. Mutations in the EGFR, ALK rearrangements, and ROS 1 are observed in approximately $20-25 \%$ of NSCLC and patients with a driver mutation usually treated with specific inhibitors (e.g., erlotinib, gefitinib, osimertinib, and alectinib) that show significant improvement compared to standard chemotherapy (CT) regimens [7-13]. Initial systemic therapy options for those without a driver mutation (approx. $75 \%$ of patients) 
are immunotherapy, immunotherapy plus CT, or CT alone when immunotherapy is contraindicated or unavailable [2, 14-16]. Delayed treatment initiation has been evaluated for a variety of solid tumors (early-stage NSCLC, breast, prostate, kidney, pancreas) treated with curative intent and was shown to be increasingly common and to negatively affect survival [17].

However, due to testing after accumulation, a need to re-biopsy, and most frequently delays in accessing preparations, tests for driver mutations take between 4 and 6 weeks. The length of this waiting period may generate anxiety in patients and clinicians alike over a possible delay in selecting a treatment and subsequent decrease in the chance of survival [18]. For this reason, an investigation was conducted into whether the duration between diagnosis and the start of first-line CT (DDC) in NSCLC patients without driver mutations has an impact on prognosis.

\section{Materials and Methods}

\section{Study Population}

The medical records of 817 patients with de novo metastatic NSCLC who had been treated with palliative CT between 2014 and 2019 in the medical oncology clinic of Istanbul were scanned. The patient staging procedure was performed according to the imaging outcomes of fluorine-18-fluorodeoxyglucose positron emission tomography/computed tomography, computed tomography, and brain magnetic resonance. The following parameters were defined as exclusion criteria: aged $<18$ years, patients with a second primary malignancy, those with benign or malign hematological disorder, patients without evidence of metastasis at diagnosis, prior exposure to tyrosine kinase inhibitors or immunotherapy, those with missing data, patients with driver mutation, and patients whose mutation status could not be evaluated. Also, patients were divided into 2 groups according to DDC: $\leq 30$ days (group A) or $>30$ day (group B; Fig. 1).

\section{Data Collection}

Demographic and disease characteristics such as age, gender, smoking history, Eastern Cooperative Oncology Group (ECOG) status, comorbidities (e.g., hypertension [HT], chronic obstructive pulmonary disease $[\mathrm{COPD}]$, diabetes mellitus [DM], and coronary artery disease $[\mathrm{CAD}]$ ), date of diagnosis, histology (NSCLC-NOS, SCC, and AC), grade, stage, metastasis status (oligo [the number of metastasis $\leq 3$ ] or multiple [the number of metastasis $>3$ ]), site of metastasis (brain, contralateral lung, liver, surrenal glands, bone, pleura, and others), grade, mutational status (EGFR, ALK, and ROS 1), start date of first-line CT, CT regimens (platinum + pemetrexed, platinum + paclitaxel, platinum + docetaxel, platinum + gemcitabine, platinum + etoposide, and platinum + vinorelbine), number of CT cycles, progression date, and last status (deceased or alive), were obtained from patients' archived files. Disease staging was performed according to the tumor, node, and metastasis (TNM) staging system. Progression-free survival (PFS) was defined as the time from diagnosis to progression.

\section{Biomarker Assessment}

EGFR mutation analysis was performed on the isolated DNA with an Easy PGX AriaDx real-time PCR device using an EasyPGX Ready EGFR mutation analysis kit prepared for EGFR. The exon

\section{Patients in the initial cohort had stage IV NSCLC ( $n=817)$}

Patients with de novo metastatic disease $(n=470)$

Patients without a driver mutations ( $n=392)$

Patients without any second malignancy $(n=381)$

Patients without missing data (study cohort $n=303$ )

Duration between diagnosis and beginning first-line CT

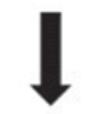

$\leq 30$ days

Group A ( $n=183)$

$>30$ days

Group B $(n=120)$

Fig. 1. Disposition of patients (CONSORT diagram).

18 codon 719 region, exon 19 deletions, exon 20 insertions and codon 768 and 790 regions, and exon 21 codon 858 and 861 regions of the EGFR gene were analyzed ( 85 possible mutation sites were examined). ALK positivity were assessed both by VENTANA ALK (D5F3) immunohistochemical assay and FISH using a Vysis ALK Break Apart FISH Probe kit (Abbott Molecular, Abbot Park, IL, USA). For ROS 1 assessment, a Vysis ROS 1 Break Apart 6q22 FISH Probe kit (Abbott Molecular) was used.

\section{Statistical Methods}

SPSS 15.0 for Windows was used for the statistical analysis. Descriptive statistics were given as a number and percentage for categorical variables, and the average, $\mathrm{SD}$, and minimum and maximum for numerical variables. Comparisons of the numerical variables in 2 independent groups were made using the Mann-Whitney $\mathrm{U}$ test, since the normal distribution condition was not met. Comparisons of the ratios in the groups were made using the $\chi^{2}$ test. The determinant factors were examined by Cox regression analysis, while a Kaplan-Meier survival analysis was performed. A statistical significance level of alpha was accepted as $p<0.05$.

\section{Results}

\section{Patient Characteristics}

The study included 303 de novo metastatic NSCLC patients without a driver mutation, consisting of $260(85.8 \%)$ males and $43(14.2 \%)$ females. The mean age was $59.9 \pm$ 11.1 years (range 21-92). Thirty-five (11.6\%) patients had no history of smoking. Of the 303 patients, 132 (43.6\%) had an ECOG performance scale (PS) of 2. The most common comorbidities were HT (17.5\%), COPD (13.2\%), 
Table 1. Patient characteristics

\begin{tabular}{|c|c|}
\hline \multicolumn{2}{|l|}{ Age at diagnosis, years } \\
\hline Mean \pm SD (min. - max.) & $59.9 \pm 11.1(21-92)$ \\
\hline \multicolumn{2}{|l|}{ Gender } \\
\hline Female & $43(14.2)$ \\
\hline Male & $260(85.8)$ \\
\hline \multicolumn{2}{|l|}{ Smoking history } \\
\hline No & $35(11.6)$ \\
\hline Yes & $261(86.1)$ \\
\hline \multicolumn{2}{|l|}{ ECOG-PS } \\
\hline $0-1$ & $171(56.4)$ \\
\hline 2 & $132(43.6)$ \\
\hline \multicolumn{2}{|l|}{ Comorbidities } \\
\hline HT & $53(17.5)$ \\
\hline DM & $8(2.6)$ \\
\hline CAD & $8(2.6)$ \\
\hline COPD & $40(13.2)$ \\
\hline \multicolumn{2}{|l|}{ Tumor histology } \\
\hline NOS & $80(26.4)$ \\
\hline SCC & $96(31.7)$ \\
\hline $\mathrm{AC}$ & $127(41.9)$ \\
\hline \multicolumn{2}{|l|}{ Grade } \\
\hline 2 & $147(48.5)$ \\
\hline 3 & $156(51.5)$ \\
\hline \multicolumn{2}{|l|}{ Metastatic status at diagnosis } \\
\hline Oligometastatic & $206(68.0)$ \\
\hline Multiple & $97(32.0)$ \\
\hline \multicolumn{2}{|l|}{ Site of metastasis } \\
\hline Brain & $121(39.9)$ \\
\hline Contralateral lung & $73(24.1)$ \\
\hline Liver & $65(21.5)$ \\
\hline Surrenal gland & $90(29.7)$ \\
\hline Bone & $148(48.8)$ \\
\hline Pleura & $64(21.1)$ \\
\hline Others & $31(10.3)$ \\
\hline \multicolumn{2}{|l|}{ DDC day } \\
\hline Mean \pm SD (min. - max.) & $38.2 \pm 54.5(0-501)$ \\
\hline \multicolumn{2}{|l|}{ DDC group } \\
\hline A & $183(60.4)$ \\
\hline B & $120(39.6)$ \\
\hline \multicolumn{2}{|l|}{ First-line CT regimen } \\
\hline Platinum + pemetrexed & $33(10.9)$ \\
\hline Platinum + paclitaxel & $71(23.4)$ \\
\hline Platinum + docetaxel & $57(18.8)$ \\
\hline Platinum + gemcitabine & $107(35.3)$ \\
\hline Platinum + etoposide & $4(1.3)$ \\
\hline Platinum + vinorelbine & $31(10.2)$ \\
\hline \multicolumn{2}{|l|}{ Number of CT cycles } \\
\hline Median (min.-max.) & $4(1-6)$ \\
\hline \multicolumn{2}{|l|}{ Progression after CT } \\
\hline No & $7(2.3)$ \\
\hline Yes & $296(97.7)$ \\
\hline \multicolumn{2}{|l|}{ Last status } \\
\hline Alive & $54(17.8)$ \\
\hline Dead & $249(82.2)$ \\
\hline
\end{tabular}

Data are presented as $n(\%)$, unless otherwise indicated. ECOGPS, Eastern Cooperative Oncology Group performance scale; DDC, duration between diagnosis and the start of first-line chemotherapy; CT, chemotherapy; NOS, not otherwise specified; SCC, squamous cell carcinoma; AC, adenocarcinoma; HT, hypertension; $\mathrm{DM}$, diabetes mellitus; $\mathrm{CAD}$, coronary arter disease; COPD, chronic obstructive pulmonary disease.
DM (2.6\%), and CAD (2.6\%). The number of patients with AC, SCC, and NSCLC-NOS were 127 (41.9\%), 96 (31.7\%), and 80 (26.4\%), respectively. Of the 303 patients, $156(51.5 \%)$ had a poorly differentiated tumor. The number of patients with oligometastatic was 206 (68.0\%). The most common sites of metastasis at diagnosis were as follows: brain (39.9\%), contralateral lung (24.1\%), liver (21.5\%), surrenal glands $(29.7 \%)$, bone $(48.8 \%)$, pleura $(21.1 \%)$, and other $(10.2 \%)$. In the first-line treatment, all patients received platinum-based combination CT. The median number of CT cycles was 4.0 (range 1-6). During the median follow-up time of 10.0 months (range 1-48) disease progressed in 296 (97.7\%) patients and 249 (82.2\%) patients died. The mean DDC was calculated as $38.2 \pm 54.5$ days. The number of patients in group $\mathrm{A}$ and B were 183 (60.4\%) and 120 (39.6\%; Table 1).

\section{Progression-Free Survival}

The median PFS was 5.0 (95\% CI 4.3-5.7) months in all patients. In the subgroup analysis, the median PFS in group A was 5.0 months (95\% CI 4.1-5.9), whereas it was 6.0 months for group B (95\% CI 4.9-7.1), indicating a statistically non-significant difference between the groups ( $\log$-rank $p=0.268$; Fig. 2).

In the univariate Cox regression analysis for PFS, including ECOG-PS, pleural metastasis, and platinum + vinorelbine were factors that negatively affected PFS, whereas the number of CT cycles was the factor associated with favorable PFS $(p<0.001, p=0.006, p=0.039$, and $p<0.001$, respectively). Likewise, in the multivariate Cox regression analysis for PFS, including the number of CT cycles was the positive predictor of PFS, whereas ECOG-PS, bone metastasis, and pleural metastasis were associated with negatively affected PFS $(p<0.001, p=$ $0.006, p<0.001$, and $p<0.001$, respectively; Table 2 ). There was no relation between DDC and PFS in the univariate or multivariate analysis.

\section{Overall Survival}

The median overall survival (OS) was 10.0 months (95\% CI 8.8-11.2) in all patients. In the subgroup analysis, the median OS in group A was 10.0 months (95\% CI 8.8-11.2), whereas for group B it was 11.0 months (95\% CI 7.8-14.2), indicating a statistically non-significant difference between the groups ( $\log$-rank $p=0.341$; Fig. 2).

Univariate Cox regression analysis for OS revealed that age at diagnosis, male gender, smoking history, ECOG-PS, poorly differentiated tumor, SCC histology, presence of multiple metastasis at diagnosis, metastasis to bone, and platinum + vinorelbine CT were the negative predictors of OS, whereas AC histology, receiving platinum + pemetrexed CT, and the number of CT cycles were the positive factors associated with OS $(p=0.006, p=$ $0.019, p=0.004, p<0.001, p=0.010, p=0.042, p=0.006$, 


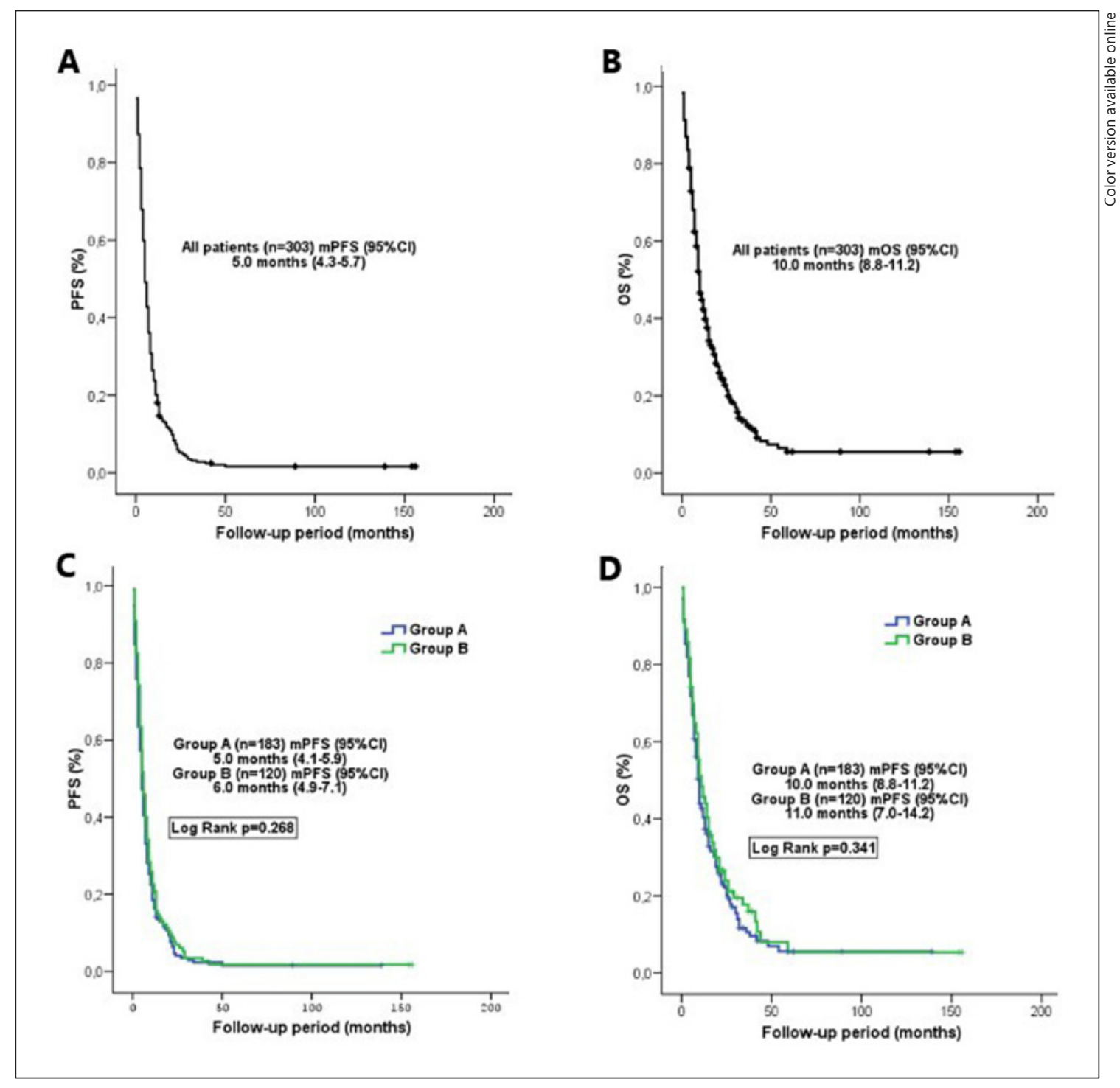

Fig. 2. Median PFS (A, C) and median OS (B, D) in all patients (A, B) and in the groups (C, D).

$p=0.005, p<0.001, p=0.002, p<0.001$, and $p<0.001$, respectively). In the multivariate Cox regression analysis, age at diagnosis, smoking history, ECOG-PS, HT, poorly differentiated tumor, and metastasis to bone were the negative predictors of OS, whereas the number of CT cycles in the first-line setting was found to be a positive predictor of OS $(p=0.022, p=0.046, p=0.010, p=0.029$, $p=0.032, p=0.027$, and $p<0.001$, respectively; Table 3 ). There was no relation between DDC and OS in the univariate or multivariate analysis.

\section{Discussion}

In this study, the prognostic impact of DDC in NSCLC patients without a driver mutation was investigated. It was demonstrated that DDC was not associated with PFS and OS, nor was there a difference between group $\mathrm{A}$ and group B in terms of PFS and OS.

There are some studies in the literature focused on the optimal time to initiate CT, mostly in an adjuvant setting. The survival benefit of adjuvant CT was shown to be time dependent, and studies have also reported that delayed CT might be associated with poor patient and disease characteristics, as well as with an increase in comorbidity in breast cancer and colorectal cancer [19-22]. Studies with similar results may cause anxiety about the waiting period in physicians and patients. For these reasons, some patients receive CT before their test results.

In a study assessing the real-world ALK testing patterns among community practices, it was found that the median time from advanced disease diagnosis to ALK test results was 29 days, and that the proportion of patients who started CT before receiving ALK test results was 21.5\%. There 
Table 2. Factors affecting PFS

\begin{tabular}{|c|c|c|c|c|c|c|}
\hline & \multicolumn{3}{|c|}{ Univariate analysis for PFS } & \multicolumn{3}{|c|}{ Multivariate analysis for PFS } \\
\hline & HR & $95 \% \mathrm{CI}$ & $p$ value & HR & $95 \% \mathrm{CI}$ & $p$ value \\
\hline \multicolumn{7}{|l|}{ Age at diagnosis } \\
\hline Years & 0.999 & $0.988-1.009$ & 0.788 & & & \\
\hline \multicolumn{7}{|l|}{ Gender } \\
\hline Male vs. female & 1.070 & $0.768-1.490$ & 0.689 & & & \\
\hline \multicolumn{7}{|l|}{ Smoking history } \\
\hline Yes vs. no & 1.106 & $0.762-1.607$ & 0.596 & & & \\
\hline \multicolumn{7}{|l|}{ ECOG } \\
\hline 2 vs. $0-1$ & 2.330 & $1.812-2.995$ & $<0.001$ & 1.953 & $1.487-2.563$ & $<0.001$ \\
\hline \multicolumn{7}{|l|}{ Comorbidities } \\
\hline $\mathrm{HT}$ & 0.804 & $0.591-1.094$ & 0.164 & 1.095 & $0.784-1.529$ & 0.594 \\
\hline DM & 0.537 & $0.253-1.14$ & 0.105 & 0.697 & $0.322-1.509$ & 0.360 \\
\hline CAD & 0.817 & $0.386-1.732$ & 0.598 & & & \\
\hline COPD & 0.618 & $0.198-1.929$ & 0.407 & & & \\
\hline \multicolumn{7}{|l|}{ Grade } \\
\hline 3 vs. 2 & 1.429 & $0.626-3.265$ & 0.397 & & & \\
\hline \multicolumn{7}{|l|}{ Tumor histology } \\
\hline NOS & 0.972 & $0.741-1.275$ & 0.837 & & & \\
\hline SCC & 0.995 & $0.779-1.272$ & 0.969 & & & \\
\hline $\mathrm{AC}$ & 0.979 & $0.775-1.236$ & 0.857 & & & \\
\hline \multicolumn{7}{|l|}{ Metastatic status } \\
\hline Multiple vs. oligo & 1.138 & $0.889-1.457$ & 0.305 & & & \\
\hline \multicolumn{7}{|l|}{ Site of metastasis } \\
\hline Brain & 0.850 & $0.672-1.075$ & 0.176 & 0.902 & $0.694-1.173$ & 0.442 \\
\hline Contralateral lung & 0.915 & $0.698-1.199$ & 0.519 & & & \\
\hline Liver & 0.999 & $0.757-1.318$ & 0.994 & & & \\
\hline Surrenal gland & 0.897 & $0.697-1.153$ & 0.395 & & & \\
\hline Bone & 1.245 & $0.989-1.568$ & 0.062 & 1.423 & $1.107-1.830$ & 0.006 \\
\hline Pleura & 1.481 & $1.118-1.962$ & 0.006 & 1.910 & $1.400-2.605$ & $<0.001$ \\
\hline Others & 1.210 & $0.829-1.768$ & 0.323 & & & \\
\hline \multicolumn{7}{|l|}{ DDC } \\
\hline Days & 0.998 & $0.996-1.000$ & 0.083 & & & \\
\hline \multicolumn{7}{|l|}{ DDC } \\
\hline$\leq 30$ vs. $>30$ days & 0.883 & $0.698-1.116$ & 0.298 & 0.854 & $0.655-1.114$ & 0.245 \\
\hline \multicolumn{7}{|c|}{ CT regimen (platinum + ) } \\
\hline Pemetrexed & 0.828 & $0.567-1.209$ & 0.329 & & & \\
\hline Paclitaxel & 1.200 & $0.914-1.576$ & 0.190 & 1.099 & $0.775-1.557$ & 0.597 \\
\hline Docetaxel & 1.076 & $0.799-1.449$ & 0.630 & & & \\
\hline Gemcitabine & 0.797 & $0.627-1.014$ & 0.064 & 0.888 & $0.660-1.195$ & 0.432 \\
\hline Etoposide & 0.934 & $0.347-2.510$ & 0.892 & & & \\
\hline Vinorelbine & 1.491 & $1.020-2.179$ & 0.039 & 1.149 & $0.741-1.782$ & 0.535 \\
\hline Number of CT cycles & 0.731 & $0.672-0.795$ & $<0.001$ & 0.727 & $0.660-0.800$ & $<0.001$ \\
\hline
\end{tabular}

Please refer to Table 1 footnote for definitions of abbreviations. Bold values are statistically significant.

was no information, however, about the mutation status of patients receiving CT before test results and the prognostic impact of early CT [18]. Similarly, in a trial published by Lim et al. [23], a total of 175 advanced non-squamous NSCLC patients who were tested for EGFR and ALK were included. Among these patients, 19\% of those with positive test results had received CT before targeted therapy. In another study including ALK and advanced NSCLC patients, it was evaluated whether receiving CT before initiation of an ALK inhibitor affects survival and it was found that patients had similar survival outcomes regardless of whether they received CT before initiation of ALK inhibitor treatment [24]. The studies presented above, however, did not compare early or delayed CT in NSCLC patients without a driver mutation.

Only patients without driver mutations were included in the present study, which evaluated whether DDC affects PFS and OS, and which demonstrated that DDC was associated with neither. Also, patients were grouped according to DDC as $\leq 30$ and $>30$ days and observed that there was no difference between groups in terms of PFS and OS. Results may be associated with a relatively higher 
Table 3. Factors affecting OS

\begin{tabular}{|c|c|c|c|c|c|c|}
\hline & \multicolumn{3}{|c|}{ Univariate analysis for OS } & \multicolumn{3}{|c|}{ Multivariate analysis for OS } \\
\hline & HR & $95 \%$ CI & $p$ value & HR & $95 \%$ CI & $p$ value \\
\hline \multicolumn{7}{|l|}{ Age at diagnosis } \\
\hline Years & 1.016 & $1.004-1.027$ & 0.006 & 1.038 & $1.005-1.071$ & 0.022 \\
\hline \multicolumn{7}{|l|}{ Gender } \\
\hline Male vs. female & 1.580 & $1.078-2.317$ & 0.019 & 1.306 & $0.487-3.508$ & 0.596 \\
\hline \multicolumn{7}{|l|}{ Smoking history } \\
\hline $\begin{array}{l}\text { Yes vs. no } \\
\text { ECOG }\end{array}$ & 1.981 & $1.250-3.140$ & 0.004 & 2.959 & $1.018-8.599$ & 0.046 \\
\hline \multicolumn{7}{|l|}{ ECOG } \\
\hline 2 vs. $0-1$ & 3.743 & $2.804-4.997$ & $<0.001$ & 3.083 & $1.305-7.285$ & 0.010 \\
\hline \multicolumn{7}{|l|}{ Comorbidities } \\
\hline HT & 0.785 & $0.555-1.109$ & 0.169 & 1.979 & $1.072-3.651$ & 0.029 \\
\hline $\mathrm{DM}$ & 0.602 & $0.267-1.357$ & 0.221 & 2.014 & $0.687-5.905$ & 0.202 \\
\hline CAD & 1.160 & $0.515-2.612$ & & & & \\
\hline COPD & 1.174 & $0.376-3.671$ & & & & \\
\hline \multicolumn{7}{|l|}{ Grade } \\
\hline 3 vs. 2 & 3.062 & $1.306-7.179$ & 0.010 & 3.539 & $1.115-11.22$ & 0.032 \\
\hline \multicolumn{7}{|l|}{ Tumor histology } \\
\hline NOS & 1.246 & $0.938-1.655$ & 0.130 & 1.689 & $0.184-15.46$ & 0.643 \\
\hline SCC & 1.313 & $1.010-1.707$ & 0.042 & 1.597 & $0.183-13.92$ & 0.672 \\
\hline $\mathrm{AC}$ & 0.663 & $0.512-0.589$ & 0.002 & 1.808 & $0.210-15.55$ & 0.590 \\
\hline \multicolumn{7}{|l|}{ Metastatic status } \\
\hline Multiple vs. oligo & 1.446 & $1.112-1.880$ & 0.006 & 0.342 & $0.094-1.246$ & 0.104 \\
\hline \multicolumn{7}{|l|}{ Site of metastasis } \\
\hline Brain & 0.831 & $0.644-1.074$ & 0.157 & 0.902 & $0.456-1.782$ & 0.767 \\
\hline Contralateral lung & 0.871 & $0.649-1.169$ & 0.357 & & & \\
\hline Liver & 0.932 & $0.688-1.263$ & 0.650 & & & \\
\hline Surrenal gland & 1.007 & $0.769-1.318$ & 0.959 & & & \\
\hline Bone & 1.433 & $1.115-1.843$ & 0.005 & 1.885 & $1.073-3.311$ & 0.027 \\
\hline Pleura & 1.093 & $0.804-1.484$ & 0.570 & & & \\
\hline Others & 1.458 & $0.989-2.149$ & 0.057 & 1.170 & $0.136-10.05$ & 0.886 \\
\hline \multicolumn{7}{|l|}{ DDC } \\
\hline Days & 0.998 & $0.995-1.000$ & 0.080 & & & \\
\hline \multicolumn{7}{|l|}{$\mathrm{DDC}$} \\
\hline$\leq 30$ vs. $>30$ days & 0.886 & $0.686-1.145$ & 0.356 & 0.922 & $0.512-1.661$ & 0.788 \\
\hline \multicolumn{7}{|c|}{ CT regimen (platinum +) } \\
\hline Pemetrexed & 0.272 & $0.144-0.513$ & $<0.001$ & 0.507 & $0.116-2.211$ & 0.366 \\
\hline Paclitaxel & 1.241 & $0.926-1.661$ & 0.148 & 1.296 & $0.643-2.611$ & 0.468 \\
\hline Docetaxel & 1.144 & $0.842-1.556$ & 0.390 & & & \\
\hline Gemcitabine & 0.875 & $0.675-1.134$ & 0.313 & & & \\
\hline Etoposide & 1.637 & $0.608-4.409$ & 0.329 & & & \\
\hline Vinorelbine & 2.109 & $1.436-3.097$ & $<0.001$ & 1.241 & $0.434-3.542$ & 0.687 \\
\hline Number of CT cycles & 0.600 & $0.547-0.660$ & $<0.001$ & 0.680 & $0.537-0.860$ & 0.001 \\
\hline
\end{tabular}

Please refer to Table 1 footnote for definitions of abbreviations. Bold values are statistically significant.

tumor doubling time in NSCLC patients than the mean DDC (38.2 \pm 54.5 days). In a study published in 2014 , it was found that the median TDT was 139 days [25]. In another trial, the median tumor doubling time of the solid component of the tumor was calculated as 175.5 days [26].

The present study has a few limitations. First, it was planned retrospectively. Therefore, there was no balancing of patient characteristics between the groups. Second, although the study included a statistically sufficient number of patients, that number could have been higher. Also, we could not evaluate whether or not DDC affected the prognosis of patients treated with an immunotherapy and CT combination. However, this is the first study focused on the prognostic impact of DDC in metastatic NSCLC patients without driver mutations.

\section{Conclusion}

Our results show that higher DDC was not associated with a worse prognosis in metastatic NSCLC patients without driver mutations. Furthermore, earlier studies 
demonstrated that early CT without additional improvement in patients with a positive test result may result in additional side effects and cost. In this context, it is safer for patients and their physicians to wait for test results before starting CT. However, these results need to be supported by prospective randomized controlled trials.

\section{Statement of Ethics}

The study was performed in accordance with the Declaration of Helsinki. The patients gave their written informed consent before the study. Both patient consent and the approval of the Health Sciences University, Okmeydani Training and Research Hospital Ethics Committee were received.

\section{Conflict of Interest Statement}

The authors declare no conflicts of interest.

\section{Funding Sources}

There was no grant funding for this study.

\section{Author Contributions}

S.A., A.S., S.C., N.Y., and R.C., planning. S.A., R.C., S.C., N.Y., and S.S., data collection. A.S., S.A, and R.C., statistical analysis.

\section{References}

1 Siegel RL, Miller KD, Jemal A. Cancer statistics, 2018. CA Cancer J Clin. 2018 Jan;68(1): 7-30.

2 NSCLC Meta-Analyses Collaborative Group. Chemotherapy in addition to supportive care improves survival in advanced non-small-cell lung cancer: a systematic review and metaanalysis of individual patient data from 16 randomized controlled trials. J Clin Oncol. 2008 Oct;26(28):4617-25.

3 Janssen-Heijnen ML, Coebergh JW, Klinkhamer PJ, Schipper RM, Splinter TA, Mooi WJ. Is there a common etiology for the rising incidence of and decreasing survival with adenocarcinoma of the lung? Epidemiology. 2001 Mar;12(2):256-8.

4 Sakin A, Sahin S, Atci MM, Sakin A, Yasar N, Geredeli C, et al. The effect of different treatment modalities on survival in elderly patients with locally advanced non-small cell lung cancer. Pulmonology. 2019 Dec;S25310437(19)30215-6.

5 Lindeman NI, Cagle PT, Aisner DL, Arcila ME, Beasley MB, Bernicker EH, et al. Updated molecular testing guideline for the selection of lung cancer patients for treatment with targeted tyrosine kinase inhibitors: guideline from the College of American Pathologists, the International Association for the Study of Lung Cancer, and the Association for Molecular Pathology. J Mol Diagn. 2018 Mar;20(2): 129-59.

6 Leighl NB, Rekhtman N, Biermann WA, Huang J, Mino-Kenudson M, Ramalingam SS, et al. Molecular testing for selection of patients with lung cancer for epidermal growth factor receptor and anaplastic lymphoma kinase tyrosine kinase inhibitors: american Society of Clinical Oncology endorsement of the College of American Pathologists/International Association for the study of lung cancer/association for molecular pathology guideline. J Clin Oncol. 2014 Nov;32(32):3673-9.

7 Shi Y, Au JS, Thongprasert S, Srinivasan S, Tsai CM, Khoa MT, et al. A prospective, molecular epidemiology study of EGFR mutations in Asian patients with advanced nonsmall-cell lung cancer of adenocarcinoma histology (PIONEER). J Thorac Oncol. 2014 Feb; 9(2):154-62.
8 Pikor LA, Ramnarine VR, Lam S, Lam WL. Genetic alterations defining NSCLC subtypes and their therapeutic implications. Lung Cancer. 2013 Nov;82(2):179-89.

9 Bergethon K, Shaw AT, Ou SH, Katayama R, Lovly CM, McDonald NT, et al. ROS1 rearrangements define a unique molecular class of lung cancers. J Clin Oncol. 2012 Mar;30(8): 863-70.

10 Zhou C, Wu YL, Chen G, Feng J, Liu XQ, Wang $C$, et al. Erlotinib versus chemotherapy as first-line treatment for patients with advanced EGFR mutation-positive non-smallcell lung cancer (OPTIMAL, CTONG-0802): a multicentre, open-label, randomised, phase 3 study. Lancet Oncol. 2011 Aug;12(8):735-42.

11 Mok TS, Wu YL, Thongprasert S, Yang CH, Chu DT, Saijo N, et al. Gefitinib or carboplatin-paclitaxel in pulmonary adenocarcinoma. N Engl J Med. 2009 Sep;361(10):947-57.

12 Soria JC, Ohe Y, Vansteenkiste J, Reungwetwattana T, Chewaskulyong B, Lee KH, et al.; FLAURA Investigators. Osimertinib in untreated EGFR-mutated advanced non-smallcell lung cancer. N Engl J Med. 2018 Jan; 378(2):113-25.

13 Gainor JF, Shaw AT. J-ALEX: alectinib versus crizotinib in ALK-positive lung cancer. Lancet. 2017 Jul;390(10089):3-4.

14 Reck M, Rodríguez-Abreu D, Robinson AG, Hui R, Csőszi T, Fülöp A, et al.; KEYNOTE-024 Investigators. Pembrolizumab versus chemotherapy for PD-L1-positive non-small-cell lung cancer. N Engl J Med. 2016 Nov;375(19):1823-33.

15 Gandhi L, Rodríguez-Abreu D, Gadgeel S, Esteban E, Felip E, De Angelis F, et al.; KEYNOTE-189 Investigators. Pembrolizumab plus chemotherapy in metastatic non-smallcell lung cancer. N Engl J Med. 2018 May; 378(22):2078-92.

16 Bozkaya Y, Köstek O, Sakin A, Özyükseler DT, Şakalar T, Çil İ. Is the prognostic nutritional index a prognostic and predictive factor in metastatic non-small cell lung cancer patients treated with first-line chemotherapy? Support Care Cancer. 2020 May;28(5):227382.

17 Khorana AA, Tullio K, Elson P, Pennell NA, Grobmyer SR, Kalady MF, et al. Time to ini- tial cancer treatment in the United States and association with survival over time: an observational study. PLoS One. 2019 Mar; 14(3):e0213209

18 Illei PB, Wong W, Wu N, Chu L, Gupta R, Schulze K, et al. ALK testing trends and patterns among community practices in the United States. JCO Precis Oncol. 2018;(2):111.

19 Xu F, Rimm AA, Fu P, Krishnamurthi SS, Cooper GS. The impact of delayed chemotherapy on its completion and survival outcomes in stage II colon cancer patients. PLoS One. 2014 Sep;9(9):e107993.

20 Hershman D, Hall MJ, Wang X, Jacobson JS, McBride R, Grann VR, et al. Timing of adjuvant chemotherapy initiation after surgery for stage III colon cancer. Cancer. 2006 Dec; 107(11):2581-8.

21 Gao P, Huang XZ, Song YX, Sun JX, Chen $\mathrm{XW}$, Sun $\mathrm{Y}$, et al. Impact of timing of adjuvant chemotherapy on survival in stage III colon cancer: a population-based study. BMC Cancer. 2018 Mar; 18(1):234.

22 Hershman DL, Wang X, McBride R, Jacobson JS, Grann VR, Neugut AI. Delay of adjuvant chemotherapy initiation following breast cancer surgery among elderly women. Breast Cancer Res Treat. 2006 Oct;99(3):313-21.

23 Lim C, Tsao MS, Le LW, Shepherd FA, Feld $\mathrm{R}$, Burkes RL, et al. Biomarker testing and time to treatment decision in patients with advanced nonsmall-cell lung cancer. Ann Oncol. 2015 Jul;26(7):1415-21.

24 Sheinson D, Wong WB, Wu N, Mansfield AS. Impact of delaying initiation of anaplastic lymphoma kinase inhibitor treatment on survival in patients with advanced non-small-cell lung cancer. Lung Cancer. 2020 May;143:8692.

25 Nakamura R, Inage Y, Tobita R, Mori K, Numata T, Yanai H, et al. Epidermal growth factor receptor mutations: effect on volume doubling time of non-small-cell lung cancer patients. J Thorac Oncol. 2014;9(9):1340-44.

26 Miura K, Hamanaka K, Koizumi T, Kawakami S, Kobayashi N, Ito KI. Solid component tumor doubling time is a prognostic factor in non-small cell lung cancer patients. J Cardiothorac Surg. 2019 Mar;14(1):57. 